\title{
CRÍTICA AO MODELO DE DESENVOLVIMENTO RURAL DE OLHOS D'ÁGUA, MUNICÍPIO DE URUGUAIANA (RS): A VOZ DOS AGRICULTORES
}

\author{
Liana Mendonça Goñi ${ }^{1}$ \\ Jaime Morales Hernández²
}

\begin{abstract}
RESUMO
O objetivo do artigo é analisar o modelo de desenvolvimento rural do distrito Olhos D'Água, bem como os diferentes agir e reagir, práticas e discursos dos agricultores e pecuaristas familiares da região de Olhos D'água. Trata-se de um estudo de caso, com abordagem qualitativa e exploratória. Para tanto, a pesquisa consiste na união de duas perspectivas metodológicas: perspectiva etnográfica ator-rede Latour e Woolgar (1997), e a perspectiva orientada desde os atores de Long (2007). A partir das análises discursivas e documentais foi possível ressaltar as diferentes agriculturas, os diferentes graus de mercantilização e as diferentes racionalidades e modos de vidas no âmbito rural da região. Ao final do estudo conclui-se que a solução ao crescimento econômico é de ordem hegemônica para todas as realidades rurais, descartando a cada território o potencial das diferentes configurações sociais/produtivas, econômicas e ecológicasos locais. Nas mesmas características de "atrasados" e "estagnados" em que os pecuaristas familiares e a pecuária familiar foram forjados, há subsídios empíricos a pensarmos em estratégias desde essas racionalidades e modos de vida.
\end{abstract}

Palavras-chave: agricultores familiares, desenvolvimento, diferentes agriculturas, pecuaristas, Uruguaiana.

\section{CRITICISM TO THE RURAL DEVELOPMENT MODEL OF OLHOS D'ÁGUA, URUGUAIANA MUNICIPALITY (RS): THE VOICE OF FARMERS}

\begin{abstract}
The aim of the article is to analyze the model of rural development in the district of Olhos D'Água, as well as the different actions and reactions, practices and discourses of farmers and family ranchers in the region of Olhos D'água. This is a case study, with a qualitative and exploratory approach. To this end, the research consists of the union of two methodological perspectives: actor-network ethnographic perspective Latour and Woolgar (1997), and a perspective oriented from Long's actors (2007). From the discursive and documentary analyzes, it was possible to

\footnotetext{
${ }^{1}$ Graduação em Tecnologia em Agronegócio (UFSM). Especialização em Desenvolvimento Territorial e Agroecologia (UERGS). Mestrado em Agroecologia (UCO). Mestranda em Gestão e Tecnologia Ambiental (UFMT). E-mail: lianagoni@gmail.com

2 Graduação em Engenharia Agronômica (ITESM). Mestrado em Agroecología y Desarrollo Rural Sustentable (UNIA). Doutorado em Agroecología (UCO). Professor investigador do Centro Interdisciplinario para la Formación y Vinculación Social (ITESO). E-mail: jaimem@iteso.mx
} 
emphasize how different agriculture, the different degrees of commercialization and how different rationalities and ways of life in the rural area of the region. At the end of the study, it is concluded that the solution to economic growth is hegemonic in all rural realities, discarding the potential of different social / productive configurations, improving and ecological locations in each territory. In the same characteristics of "backward" and "stagnant" in which family ranchers and family ranching were forged, there are empirical subsidies to think of strategies from these rationalities and ways of life.

Keywords: development, different agriculture, family farmers, ranchers, Uruguaiana.

\section{INTRODUÇÃO}

Neste trabalho pretendemos analisar o modelo de desenvolvimento rural do distrito Olhos D'Água. À luz das interações rurais e suas realidades heterogêneas, expor dinâmicas da modernização da agricultura, através de uma perspectiva desde os atores Long (2007), Ploeg (1993; 2006; 2008).

Diversas questões referentes ao desenvolvimento e seus pressupostos emergem no início do século XXI. Desde América Latina, o Pós - Desenvolvimento iniciou o diálogo das subjetividades do desenvolvimento e como ele se introduziu (introduz) nas diferentes realidades, através do discurso homogêneo, simplista e preconceituoso. O porquê, cotidianamente, outras culturas e epistemologias sofrem ações modernizantes e simplificadas por um modelo de lógica ocidental e/ou estadunidense, é uma das interrogativas da teoria Pós-Desenvolvimentista, bem como a imprescindível necessidade da desconstrução dos discursos homogêneos e coloniais, e a eminente necessidade de repensar próprias necessidades locais emergentes (ESCOBAR, 1999).

A teorias pós-estruturalistas atuam através da interpretação e construção com a finalidade de representar aos atores sociais, discursos e conhecimentos. Somando a pluralidade dos discursos como elemento de mudança, sobretudo, na observação das resistências dos atores e como eles subvertem o conhecimento dominante em conhecimentos "outros". (ESCOBAR, 2005).

A partir da década de oitenta surge uma necessidade de superar debates estruturalistas referentes ao desenvolvimento e suas teorias metodológicas limitadas. Um dos caminhos foram as alternativas metodológicas centradas no ator, onde considera as pessoas como participantes ativos nos processos e ações (LONG, 2007).

A potente ferramenta institucional chamada de desenvolvimento rural, tomou como contrapartida a modernização de grandes e médias propriedades rurais, que através de subsídios do governo, modernizaram-se após a Segunda Guerra Mundial. A Revolução Verde consolida-se através dos complexos agroindustriais e as atividades não agrícolas. Fenômenos também chamados de "modelo de modernização conservadora3" no país (GRAZIANO DA SILVA, 1996).

De acordo com Long (2007), a modernização se alastra junto ao desenvolvimento através do progresso e a formas complexas de cunho institucional

\footnotetext{
${ }^{3}$ A modernização conservadora deu-se início a partir do Regime Militar, no Golpe de Estado de 1964. Além do discurso de repressão, havia o discurso da necessária modernização do Brasil. A agricultura passou a interagir com mais intensidade com os mercados e ao uso de tecnologias avançadas. Essa interação trouxe a acelerada desigualdade social no país e a denominação "modernização conservadora", acabou tornando se na explicação que acarretou os principais problemas sociais no meio rural brasileiro (GRAZIANO DA SILVA, 1996).
} 
e tecnológico. O processo, no meio rural, se dá pela conexão com os mercados e a inserção dos agricultores "tradicionais e atrasados", às tecnologias, conhecimentos, recursos e distintas formas de organização (através das formas de intervenção). Projeto em que a sociedade tradicional passa a ser inserida a padrões econômicos e sociais já pré-estabelecidos pelo mundo moderno.

Equiparando a historicidade ao âmbito regional, o Rio Grande do Sul metabolizou tais ações modernizantes em fluxos dessemelhantes. Na região sul do estado gaúcho, a então recortada "metade sul", historicamente, foi sustentada pela atividade agropecuária por grandes latifúndios (doado pela colônia portuguesa, através das sesmarias). Já a região norte do estado configurou-se por outros arranjos imigratórios e configurações sociais distintas, que ocasionaram então, peculiaridades culturais, produtivas, econômicas e ecológicas entre as regiões sul e norte do estado (CARGNIN, 2014).

Por tratar-se de uma atividade pouco mercantilizada, a pecuária e a "metade sul" passaram a ser alvos do desenvolvimento. O governo, a partir da metade do século passado, lançou planos de desenvolvimento rural equivocados, arriscados e milagrosos às características endógenas regionais. Tais medidas tinham como principal intenção a imposição da região sul as características produtivas/sociais, ecológicas e culturais da região norte.

A modernização da agricultura é uma externalidade que auxilia novas relações mercantis e técnico-administrativas a todo momento. Ela causa rupturas no que diz respeito às tarefas do trabalho agrícola, as designando a agentes externos e ocasionando a crescente divisão do trabalho e da indústria (PLOEG, 1993).

Acompanhando a imersão do estado à modernização da agricultura, o município de Uruguaiana, integrante da região sul do estado, está localizado na região da campanha gaúcha ${ }^{4}$, e é um dos principais produtores de arroz irrigado do Rio Grande do Sul, estado líder na produção a nível nacional (IRGA, 2015). Segundo a Associação Rural de Uruguaiana (2006), a ação modernizante teve início nos anos setenta, entretanto o cultivo do arroz já era exercido no município desde a década de quarenta.

O cultivo de arroz na região concretizou-se, inicialmente, pela agricultura empresarial e os maiores adeptos as novas dinâmicas foram os médios e grandes produtores e arrendatários. Com o passar das décadas a modernização foi adaptada aos agricultores familiares da região, formando um mosaico produtivo heterogêneo a partir de uma dinâmica distinta comparada a agricultura empresarial, o que Long (2007) propõe como capacidade de agência (ação).

Os agricultores(as) e pecuaristas familiares foram introduzidos a essas dinâmicas modernizantes, caracterizando diferentes agriculturas com diferentes graus de mercantilização (PLOEG 1993; 2006; 2008). Configurando diferentes estratégias multi-uso, o que Toledo (1993) nomeia de diferentes valores de uso e racionalidades ecológicas, onde bens são produzidos a fim de atender as necessidades da família, proporcionando sua maior autossuficiência.

Desse modo, o artigo está estruturado em quatro seções. A primeira está contida nesta introdução. A segunda explanamos os métodos da pesquisa, entrevista e análise de dados. A terceira buscamos analisar a atividade da pecuária e o modelo de desenvolvimento da região e os principais resultados e formas de agir e reagir dos pecuaristas, agricultores e trabalhadores rurais da região. Por fim, a

\footnotetext{
${ }^{4}$ Quando usado o termo campanha gaúcha nos referimos à região Sudoeste Gaúcho (Aceguá, Alegrete, Bagé, Barra do Quaraí, Dom Pedrito, Garruchos, Hulha Negra, Itaqui, Lavras do Sul, Maçambara, Manoe Viana, Rosário do Sul, Santa Margarida do Sul, Santana do Livramento, São Borja, São Francisco de Assis, São Gabriel e Uruguaiana).
} 
quarta seção está composta pelas considerações finais referentes as seções anteriores da pesquisa.

\section{MÉTODOS}

Esta pesquisa trata-se de um estudo de caso, através de uma abordagem qualitativa e exploratória. O estudo de caso segundo Gil (2008), é caracterizado através do estudo profundo de um ou poucos objetos.

A pesquisa consiste em duas fases metodológicas: primeira fase é a utilização da perspectiva etnográfica ator-rede de Latour e Woolgar (1997), cabendo ao pesquisador seguir os atores (humanos e não humanos) através das redes em que se inserem, descrevendo seus enredos, conexões e relações. Oportunizando verificar as diferentes agriculturas e dar a voz a esses agricultores(as) e pecuaristas; e a segunda fase desprende-se das limitações teóricas do desenvolvimento e modernização da agricultura utilizando a perspectiva orientada desde os atores de Long (2007).

O município de Uruguaiana está localizado na extremidade meridional do país, no estado Rio Grande do Sul. Distribuído pelos distritos: Distrito Vertentes (onde se encontra a região estudada Olhos D'água), Plano Alto, João Arregui e São Marcos. Faz fronteira com os países Argentina e Uruguai e está inserido no Bioma Pampa.

Como coleta de dados utilizou-se a entrevista semiestruturada com os agricultores, trabalhadores rurais e pecuaristas familiares. Com a pesquisa sendo realizada a campo, a pesquisadora teve maior riqueza de detalhes, maiores informações referente as diferentes realidades dos atores sociais e maior liberdade para condução das conversas e dados e materiais pertinentes a pesquisa.

O questionário seguiu o objetivo da pesquisa de analisar o modelo de desenvolvimento da região: informações gerais da propriedade e história, autonomia, mudanças produtivas e sociais, perspectivas da produção e características do uso da terra. A pesquisa foi realizada no mês de julho de 2015. A escolha do município e distrito foi justifica-se por haver as atividades da pecuária familiar e o cultivo do arroz concomitantemente, pelo menos, quarenta anos na região.

No quadro 1, estão ilustradas as categorias de análise do artigo. Estão expostas características principais para as posteriores análises das diferentes agriculturas. 
Quadro 1 - Configuração e caracterização dos entrevistados

\begin{tabular}{|l|l|l|}
\hline Nomes & Informante direto & Lugar de residência \\
\hline Agropecuarista familiar (AP) & $\begin{array}{l}\text { Homem de mais ou menos 60 anos, } \\
\text { possui terra, planta arroz, cria bovino } \\
\text { e ovino. Possui vaca de leite, porcos, } \\
\text { galinhas e cavalos. Vende produtos } \\
\text { como queijo e salame provindo de } \\
\text { sua própria atividade. Arrenda outros } \\
\text { campos para a atividade da pecuária } \\
\text { e arroz. }\end{array}$ & \\
\hline Pecuarista Familiar (PF) & $\begin{array}{l}\text { Homem com aproximadamente 50 } \\
\text { anos, pecuarista com terra própria. } \\
\text { Possui domicílio em Uruguaiana, } \\
\text { vive parcialmente no âmbito rural. }\end{array}$ & $\begin{array}{l}\text { Nasceu na região Olhos } \\
\text { D'água, e atualmente vive } \\
\text { parcialmente na cidade e } \\
\text { na propriedade rural. }\end{array}$ \\
\hline Pecuarista Familiar 1 (PF1) & $\begin{array}{l}\text { Homem com mais ou menos 90 } \\
\text { anos. Proprietário de terra. Pai do } \\
\text { PFA2 e AP. }\end{array}$ & $\begin{array}{l}\text { Reside na região Olhos } \\
\text { D'água. }\end{array}$ \\
\hline Pecuarista Familiar & $\begin{array}{l}\text { Irmão do AP, homem com mais ou } \\
\text { menos 55 anos, reside com o pai } \\
\text { Arrendatário 2 (PFA2) }\end{array}$ & $\begin{array}{l}\text { Reside na região Olhos } \\
\text { D'água e cidade de }\end{array}$ \\
\hline Uruguaiana. \\
\hline Urabalhadora residência em
\end{tabular}

Juntamente ao questionário houve o levantamento de dados secundários a partir de dados de sites governamentais de estatística e geografia, Universidades, Instituições, artigos científicos e livros sobre a história social, produtiva e ecológica da região. A pesquisa contou com documentos do município de Uruguaiana (Sindicato Rural), que proporcionou uma riqueza de informações e discursos referente a implantação do cultivo do arroz, na região. Os objetivos centrais da coleta de foram analisar a economia agropecuária da região, dados quantitativos sobre a produção de arroz e sua história e a relevância da pecuária e relação desses dados aos discursos de desenvolvimento rural no campo institucional, e tecno-científico.

Referente as técnicas de análise dos dados coletados, recorreu-se a análise de discurso, sendo a principal via de análise. Para Foucault (1979), o discurso produz coisas, verdades, etc. $O$ discurso aqui não se trata exclusivamente sob as intencionalidades do dizer, e sim de que forma os discursos se revelam ao passo que as práticas que constituem os objetos que se planteiam.

Ademais ao reconhecimento dos discursos e práticas dos agricultores e pecuaristas, a análise do trabalho baseia-se no reconhecimento da memória oral dos entrevistados. Apesar do curto tempo para a pesquisa a campo, as entrevistas 
possibilitaram que diferentes realidades fossem expostas perante diferentes modos de vida. Os seis entrevistados disponibilizaram discursos que foram essenciais para o entendimento de como certos fenômenos se instalaram e se repercutiram (repercutem) na região e possibilitaram documentos pessoais que evidenciam a história da região.

As memórias individuais corroboram à riqueza regional de histórias e de compreender a partir dos próprios protagonistas da história que trazem consigo sua marca peculiar de experiência, sem necessariamente estar comprometido com a "verdade constitucionalizada" ou vozes que no passado foram ouvidas (BOSI, 1994).

\section{PECUÁRIA E O DESENVOLVIMENTO: A DIFÍCIL SIMETRIA}

Uma das principais ameaças ao bioma pampa, a atividade da pecuária e a cultura do gaúcho estão intimamente relacionadas a atividades que dependem da supressão da vegetação nativa para sua edificação. A difícil simetria está relacionada ao projeto hegemônico do desenvolvimento que adere a essas atividades como provedoras do crescimento econômico e desenvolvimento de regiões "atrasadas". Nas duas seguintes seções propomos discutir as questões da pecuária, cultura, ecologia e economia da região Olhos D'água que está inserida no bioma pampa, e as diferentes racionalidades, estratégias e discursos dos atores sociais inseridos na dinâmica do desenvolvimento da região.

A região é caracterizada, historicamente e economicamente, pela atividade da pecuária. A partir da modernização da agricultura, neste caso a lavoura de arroz, foi implementada em meados da década de setenta. Com a modernização e a mercantilização do espaço rural, a região imergiu por profundas mudanças sociais, produtivas, ecológicas e econômicas que desfavoreceram, principalmente, a permanência e a reprodução social aos que não aderiram por completo as mudanças. Os depoimentos dos entrevistados tinham como principal objetivo a visão, desde esses atores, de como se implantou o desenvolvimento rural na região. Bem como a possibilidade de dar a voz aos relatos e experiências de vida, sentimentos e como eles entendiam o seu modo de produção e as mudanças que ocorreram nas últimas décadas e suas perspectivas de futuro.

A linha tênue que configura os estilos de agriculturas mais ou menos mercantilizadas, nos possibilita analisar como as vias de atuações do projeto de desenvolvimento se configuraram nas diferentes realidades. A ação do desenvolvimento interage através de seus discursos e práticas, enquanto as atividades rurais respondem em diferentes estratégias. Algumas são respaldadas pelas medidas desenvolvimentistas. Outras, a exemplo da pecuária "pré-moderna", servem como forma de resistência e reprodução social e ecológica, ao sistema hegemônico da modernização.

Através dos dados estatísticos podemos perceber as disparidades que 0 desenvolvimento retroalimenta em Uruguaiana: os grandes produtores com $87 \%$ das áreas rurais do município, detêm somente $30 \%$ das propriedades rurais. Enquanto os agricultores(as) familiares têm $70 \%$ das propriedades rurais e $23 \%$ em área (IBGE, 2013). Nos distintos graus de mercantilização podemos observar agriculturas com maior integração ao mercado e indústria (lavoura de arroz) e agriculturas com menor integração (pecuária familiar).

Os pecuaristas familiares associam a natureza e a cultura como constituintes do sistema produtivo de suas atividades, riqueza sociocultural que lhes foi transferido de geração em geração. 


\begin{abstract}
A pecuária se beneficia diretamente da vegetação nativa que ocorre naturalmente na região. São milhares de espécies que crescem e produzem forragem para o gado, dependendo apenas do sol, da água da chuva e da fertilidade natural do solo para o seu desenvolvimento. [...] é possível produzir proteína animal (alimento de alta qualidade), sem a necessidade de intensificar os sistemas de produção. Assim, o pecuarista não tem os custos de compra de sementes, adubação, aplicação de agrotóxicos, maquinário. [...] a produção pecuária em campo nativo é a atividade econômica mais vocacionada para a região. (PILLAR; LANGE, 2015, p.126).
\end{abstract}

Quando possibilitamos outro olhar para a pecuária, percebemos a vocação da atividade para região, ressaltando as configurações históricas em que a pecuária coevoluiu junto ao bioma pampa constituindo a cultura do gaúcho. A atividade esteve inserida nos processos sociais/históricos, ecológicos, políticos e econômicos do estado gaúcho. Com a inserção da modernização da agricultura como projeto de desenvolvimento para o estado do Rio Grande do Sul, a supressão da vegetação nativa e a conversão para a agricultura moderna, trouxe à população rural a dependência de pacotes tecnológicos, às oscilações do mercado internacional e à mudança climática, tornando a população rural vulnerável a condições externas globais (PILLAR; LANGE, 2015).

O maior equívoco dos projetos de desenvolvimento rural é não levar em consideração as características endógenas das regiões. A heterogeneidade das diferentes estratégias são resistências à permanência no campo. A dependência das famílias na cadeia produtiva do agronegócio, as tornam vulneráveis a sua capacidade de decisão que perpassa pelas questões referentes a reprodução social e ecológica da família.

A questão social, ecológica e cultural do gaúcho, os campos sulinos e a atividade da pecuária, é de evolução histórica e de extrema relevância social, ecológica e econômica para o sul do estado. Para Pillar e Lange (2015) a cultura construída há séculos por relações históricas da região é estreitamente vinculada com a natureza, desde os costumes, danças, histórias e lendas, estão na memória da sociedade e extrapola fronteiras políticas no sul da América do Sul.

A cultura e o pecuarista não existem sem o bioma pampa, e o bioma pampa tampouco existe sem o pecuarista e a cultura. A supressão do campo nativo/bioma pampa oferece desconexão do gaúcho e o natural: elos imprescindíveis ao fomento do patrimônio cultural do estado. Já se é comum analisar a modernidade como um potente discurso homogeneizante de modelos de vida, podendo assim, como nos propõe Graziano da Silva (1996), extinguir realidades que a ela não são válidas, a agricultura familiar.

Há diversos estudos que ressaltam a importância do manejo no Bioma Pampa através da pecuária, a favor da preservação dos campos nativos que hoje são severamente ameaçados por conta da conversão produtiva, neste caso da pesquisa, do cultivo de arroz. A racionalidade produtivista tem como projeto a supressão dos campos nativos em pastagens, lavouras ou árvores exóticas. A consequência dessas atividades oferece desiquilíbrios no que se refere as desigualdades sociais, o empobrecimento biológico dos campos e a perda de biodiversidade. E nessa análise que surge a palavra "vocacional", o uso de regiões cuja vocação é a pecuária estão cada vez mais sendo reconvertidas para a agricultura, principalmente soja e na região estudada, o arroz (PILLAR; LANGE, 2015). 
Entende-se a palavra "vocação" do bioma pampa como:

A vegetação nativa faz da atividade pastoril a vocação natural do Pampa. Em razão das características do meio, a pecuária extensiva possibilita a convergência de objetivos econômicos e conservacionistas no bioma, desde que respeitados alguns preceitos técnicos, como, por exemplo, o correto ajuste da carga animal. Cabe ressaltar, ainda, a importância da pecuária para a economia do Rio Grande do Sul e para a própria identidade cultural do gaúcho, que há quase 400 anos convive com a atividade pastoril. (SANT'ANNA, 2016, p.178).

Ao contrário do que citam as teorias hegemônicas da modernização, apesar de alguns entrevistados estarem inseridos a níveis maiores de mercantilização, todos os entrevistados possuem relação com a pecuária (seja ela de leite ou de corte). Inclusive os trabalhadores rurais que vendem sua mão-de-obra às estâncias vizinhas e trabalham na manutenção desses animais. Os três pecuaristas familiares como Pillar e Lange (2015) nos possibilita relacionar, são pecuaristas "tradicionais" que possuem discursos, práticas e grau de mercantilização heterogêneos entre si.

A produção de arroz da região é voltada ao mercado/consumo interno, e utiliza-se de pacotes tecnológicos e incentivos à produtividade. O cultivo está voltado ao mercado interno, porém a racionalidade produtiva não ultrapassa as bases hegemônicas da modernização e mercantilização da atividade.

Apesar de deter mais de 81 mil hectares em área plantada de arroz, o município de Uruguaiana estava em 4ํlugar, em 2013, no ranking dos maiores produtores de bovinos no estado, por volta dos 355 mil cabeças bovinas (e mais de 206 mil cabeças de ovinos), enquanto o primeiro maior produtor era o município vizinho de Alegrete, que estava por volta dos 633 mil cabeças (IBGE, 2013).

Portanto, podemos ressaltar que ao contrário da teoria simplista do desenvolvimento que nos remetem às ações hegemônicas modernizantes, Long (2007), Ploeg (2000; 2006; 2009) nos afirmam que existem diferentes reações contrárias e heterogêneas que diferenciam as agriculturas entre si, a partir das racionalidades dos próprios atores sociais. Ainda que a modernização seja legitimada nas propriedades rurais da região, a pecuária resiste como atividade vocacional da região, por se tratar se uma atividade que utiliza a vegetação natural e cultura do saber fazer, historicamente construídas.

Enquanto o arroz é introduzido como a atividade moderna à região, as racionalidades dos pecuaristas, ditos como "tradicionais", interagem entre os significados onde a atividade da pecuária está circunscrita em relações iguais as questões naturais e sociais, o que Escobar (2012) denomina de ontologias relacionais. Onde nada, seja humano e não humano, preexiste antes das relações que nos constituem. O que Toledo (1993) denomina de valores de uso e racionalidades ecológicas.

\section{AGIR E REAGIR: FORMAS DE RESISTÊNCIA FAMILIARES}

A estrutura fundiária do Rio Grande do Sul foi originada pela concessão das sesmarias a partir do século XVII. Portanto, a partir das sesmarias a Coroa Portuguesa efetivou o controle e defesa do território e a formação dos grandes latifúndios chamados de "estâncias", através da produção da pecuária. Atividade viável a partir da introdução da espécie vacum desde a época jesuítica. Foi no início do século de XIX, que as regiões pouco exploradas basicamente na região norte, 
passou a ser ocupadas pela imigração europeia, não ibérica, em dois momentos históricos: início em 1824-1890 e a última em 1920.

Referente a construção da cultura gaúcha, desde a chegada dos Portugueses no território do estado, a visão dos gaúchos foi construída e carregada de pré-conceitos. Esses homens vistos como sem religião e sem moral, eram indígenas ou mestiços que ganhavam denominação de gaúcho. Eles não possuíam propriedades e subsistiam entre roubos e vendas de produtos que os mesmos confeccionavam. Eles tinham o domínio do trabalho com a pecuária e seus saberes vinham dos indígenas minuanos, charruas e guaranis, juntamente com os cavaleiros missioneiros e pampeanos. Ao contrário da construção histórica, os gaúchos não são os grandes latifundiários e até hoje lutam pela posse de terra ou subsistem entre grandes produtores de pecuária e grandes agricultores empresariais e capitalistas (MAESTRI, 2000).

A pecuária familiar foi reconhecida institucionalmente após os anos 2000, com características distintas à agricultura familiar, porém com racionalidades similares. A principal diferença entre as categorias é a bovinocultura de corte ser a principal atividade da pecuária familiar (RIBEIRO, 2008). A pecuária familiar possui estratégias próprias e restritas as diferentes especificidades locais. Isto é, há distintas tipologias na pecuária familiar, onde os fatores internos e externos são metabolizados, delineando diferentes graus de mercantilização, estratégias e lógicas com o mercado (SANDRINI, 2005).

A pesquisa demonstra que os entrevistados detêm a mão-de-obra familiar como principal força de trabalho. O entrevistado (AP) cultiva arroz e possui um funcionário assalariado que o ajuda na atividade da pecuária e quando é época de colheita. A contratação é temporária, pois todo o manejo da lavoura é realizado pela família. Outra característica no que se refere ao acesso as terras na região, todos os entrevistados possuem suas propriedades por herança familiar ou herdadas por matrimônio.

$\mathrm{Na}$ propriedade de (AP) possuem dois silos (grandes edificações para o armazenamento do arroz para quando colhido). Um exemplo claro da modernização, uma tecnologia monumental, uma imposição visual comparada as estruturas da pecuária (que pouco necessita de grandes estruturas para seu manejo). Os silos podem ser notados de longe, um dos tantos exemplos de imposições visuais do "moderno" e "tecnológico" da modernização. Esta imposição subjetiva e silenciosa é um exemplo claro do que as teorias pós-desenvolvimentistas, de Escobar (2005), nos possibilitam relacionar, o discurso de desenvolvimento através também de práticas com potencial impositivas e subjetivas através de edificações modernas e magistrais.

Acompanhando este raciocínio da modernização da agricultura, o estudo testemunha que o entrevistado acima (AP), possui maior dependência de insumos químicos e um grau de mercantilização maior equiparados aos outros entrevistados, pois o cultivo de arroz é altamente dependente do mercado (maquinário e insumos químicos). Ele também possui um discurso produtivista em relação a propriedade, pois está intimamente introduzido a racionalidade mercantilista, através do mercado arrozeiro: "Dependo de crédito rural. Até o momento dependo de crédito, de, de crédito. (...) Tem que investir em pecuária, fazer P-R-O-D-U-Z-I-R, ter o produto, sair o produto do campo. (...) As vacas tem que dar cria, tem que sair o terneiro. A ovelha tem dar cria pra sair o cordeiro, pra ti poder ter lucro... Tem que tirar o produto pra vender." (Trecho da entrevista com AP).

Mesmo que a mercantilização estabeleça processos em que o ambiente capitalizado exerce forças "externas" (figura 1) no âmbito dos agricultores (exemplos: preços estabelecidos, tecnologias, políticas públicas, entre outros.), 
dentro dessas circunstâncias, os agricultores possuem um espaço onde eles podem exercer sua resistência e suas estratégias, a partir da capacidade de agência humana (LONG, 2007; LONG; PLOEG, 2011).

Abaixo na figura 1, está representada as diferentes estratégias e agriculturas dos entrevistados, baseado nas teorias de Long e Ploeg (2011), elaborada pelos autores.

Figura 1 - Diferentes estratégias e diferentes agriculturas

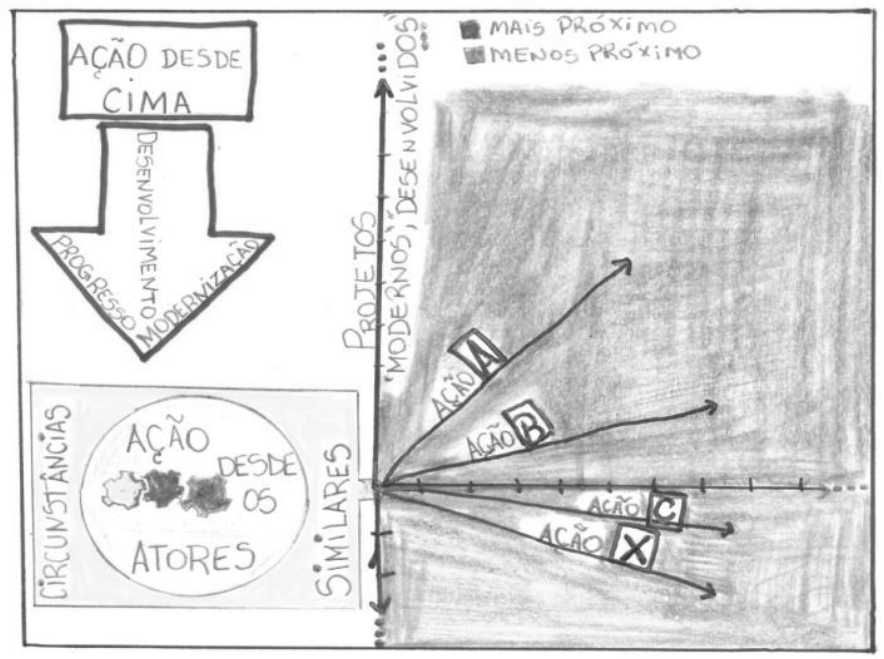

Fonte: Goñi e Hernández (2015)

O entrevistado (AP) é o produtor que mais se alinha as dimensões mercantis, relacionadas ao arroz. Entretanto, ele ressalta a resistência em aplicar os devidos volumes de insumos químicos na lavoura (como os técnicos da extensão rural o aconselharam), ou seja, apesar de ter um grau de mercantilização maior, a metabolização das ações modernas da lavoura ainda perpassa por decisões e estratégias dos produtores. Há estratégias em que agroquímicos não são administrados pela impossibilidade de pulverização de agroquímicos e quantias de água não adicionadas a lavoura por deficiência hídrica futura.

Outro motivo do racionamento do uso de insumos e da água, se dá pela baixa compensação pelo preço do arroz por saca: "Tu gasta quase $R \$ 40,00$ pra plantar arroz e $\mathrm{R} \$ 28,00$ pra vender. Para cada bolsa ter uma defasagem de $\mathrm{R} \$ 12,00, \mathrm{R} \$ 13,00 . "$ (Trecho da entrevista com AP). Apesar de ser a propriedade mais mercantilizada do estudo, há inúmeras dificuldades no plantio, justamente pela dependência da produção. O entrevistado possui 44 hectares em área plantada de arroz, e confirma que a área é insuficiente para o cultivo de arroz ser rentável.

Acompanhando a similaridade dos outros entrevistados, a pecuária é o carro chefe na propriedade. Ele conta seu imenso orgulho e satisfação e relata muitos conhecimentos empíricos da atividade, herdado de seu pai e antepassados. Nas figuras abaixo (figuras 2 e 3) estão ilustradas a atividade da pecuária na década de 80 , fotos disponibilizadas pelo entrevistado. 
Figura 2 - Foto da atividade de castração na década de oitenta em uma Estância da região. Acervo do entrevistado $\mathrm{AP}$.

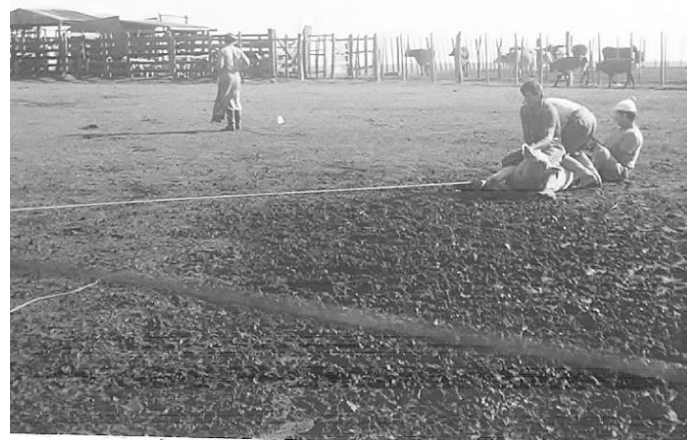

Fonte: Pesquisa de campo, 2015.

Figura 3 - Foto da "doma" gaúcha na região Olhos d' Água na década de 80. Acervo do entrevistado AP

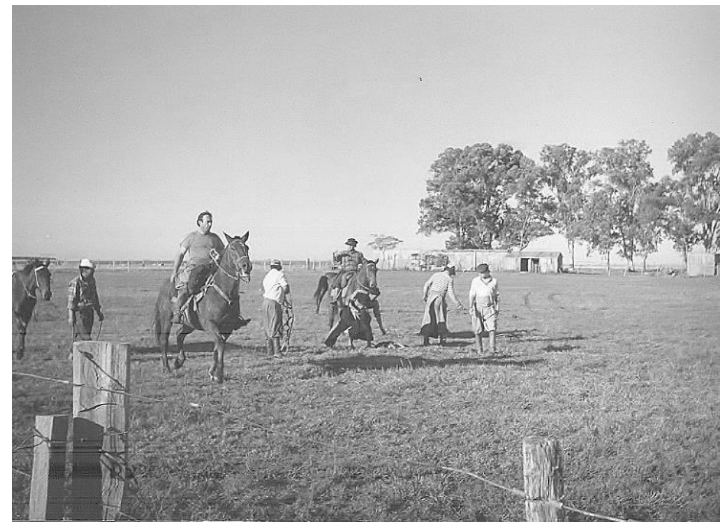

Fonte: Pesquisa de campo, 2015.

Quando o assunto é a reprodução social na propriedade, a estratégia é de suspender a atividade da lavoura de arroz (especialmente pela dependência de insumos, instituições financeiras e pela degradação do solo). Outra característica interessante é que o entrevistado exerce outras atividades que agregam a renda da família: criação de galinhas, suínos e bovino de leite. Produz queijo, linguiça, salame e ovos. Tudo comercializado diretamente com os consumidores ou pequenos estabelecimentos comerciais. Todas essas atividades são complementares na renda familiar, portanto a principal fonte de renda é a pecuária.

No trecho do entrevistado (PF), que possui somente a atividade da pecuária na propriedade, podemos observar a importância do meio natural para o desenvolvimento da atividade econômica do pecuarista: "Hoje, eu. Eu não arrendo! E não aconselho a ninguém arrendar. Pela dificuldade que está com os arrozeiros, infelizmente, tá? E para o solo, não fazem a correção necessária. E a invasão de ervas daninhas como está..." (Trecho da entrevista com PF).

O discurso dos atores também nos proporciona a noção da racionalidade como uma propriedade intrínseca do ator individual. Discurso são expressões 
individuais de como uma sociedade vive, suas racionalidades e buscas por seus próprios objetivos, estejam conscientes ou não (LONG, 2007).

Em outro trecho do mesmo entrevistado evidencia-se a procura por outros conhecimentos para tornar a pecuária rentável e ao mesmo tempo harmoniosa com o meio natural: "E eu participo um monte de palestras de... Teve de corte lá em Santa Maria, e eu vou também. Tem... Um professor lá da Universidade de Pelotas "Professor", seguida está fazendo cursos aí, eu participo. E com veterinário, que eu acompanho também, né?! Eu tenho essa possibilidade." (Trecho da entrevista com PF).

A procura por aperfeiçoamento na pecuária que unam o campo nativo e a maior rentabilidade se caracteriza pelo espaço de manobra, que Long (2007) denomina de capacidade de agência, no que se refere as decisões na atividade da pecuária, respeitando o meio natural. O espaço de manobra de (PF) que possui somente a pecuária como atividade é maior comparada ao produtor (AP), pelo último estar dependente de instituições financeiras.

O próximo entrevistado (PF1) possui 90 anos, é um antigo "estancieiro" da região e trabalha com pecuária. Ao decorrer das décadas e as doações por heranças, sua parcela de terra gradualmente foi diminuindo: "Eu tinha campo, e depois com as heranças foi diminuindo. Hoje o que tenho está bom para mim, não é muito, mas está bom para nós. Já fui grande, mas agora não sou e não posso cuidar." (Trecho da entrevista com PF1).

Ele relata que por mais de setenta anos exerceu a atividade da pecuária. Nos últimos cinco anos o pecuarista passou a arrendar uma parcela de sessenta hectares de campo para o cultivo de arroz, pela falta de mão-de-obra e a idade avançada do pecuarista.

Pillar e Lange (2015) afirmam que após a década de sessenta houve diferenciações entre os modelos de produção na pecuária em: pecuária "tradicional" e pecuária empresarial. A primeira sendo a maior parcela dos pecuaristas do estado. Mudanças incentivadas, também, pelo fracionamento das áreas produtivas (incentivado por heranças familiares), aumento no número das unidades produtivas, e a redução das áreas por estabelecimentos. Apesar dessa transformação de "estâncias" de sesmarias em "estâncias" menores, a pecuária ainda prevaleceu como principal atividade.

O entrevistado acima queixa-se de sua idade e não conseguir realizar os exercícios diários do campo. Apesar de arrendar uma parcela do campo, ele conta a relação do irmão já falecido com o plantio de arroz e ressalta a discordância com a atividade: "Mas pá, me matam tudo os peixes dos açude com os veneno. Eu não gosto, sinceramente (lavoura de arroz). Mas dizem que quando acontece isso, te digo quando dá problema com a pecuária, o arroz é melhor. Mas eu não acho, por que se dá um problema aí? Com o arroz? Perde tudo e fica sem nada." (Trecho da entrevista com PF1).

Outro trecho que o pecuarista ressalta os reflexos negativos referentes ao arrendamento para o arroz: "Os campos ficam cheio de espinho e eles não arrumam e fica tudo cheio de taipa os campos, cheio de taipas. Estropeia meu cavalo, mas é horrível." (Trecho da entrevista com PF1). Está claro que a visão do entrevistado percorre pelas racionalidades que Toledo $(1993,2008)$ esclarece como racionalidades ecológicas, e Escobar (2012) de ontologias relacionais.

O discurso a favor da pecuária e tradição gaúcha, são as principais preocupações do entrevistado neste trecho: "Os filhos já não querem as mesmas coisas. Querem viver na cidade. Querem ficar lá, a vida para o campo é difícil para muita gente, eu não sei viver sem estar aqui. Eu saio daqui eu morro." (Trecho da entrevista com PF1). Relação de pertencimento ao local é presente em seu discurso. 
Além de proporcionar a ideia de necessidade da relação com o meio natural, é colocado o valor simbólico que a atividade rural, junto as características ecológicas, apresentam para o seu modo de vida: "Sem a terra não existe nada, sem água não tem arroz. (Trecho da entrevista com PF1).

Como Toledo e Barrera-Bassols (2015) citam, a natureza não é somente um meio de produção. A natureza é um núcleo onde essas outras cosmovisões estão ancoradas. A partir dela a cultura e a identidade étnica se revelam e coevoluem. Portanto há um equívoco quando as cosmovisões são denominadas de "tradicionais", a denominação nada mais é que uma projeção da modernidade, onde há uma tentativa de simplificação de uma complexa resistência social e histórica. Uma tentativa de minimizar a faceta da evolução social, apesar da imposição da modernidade, que não sacrificou sua identidade e memória histórica para subsistir.

Na figura abaixo (figura 4), está uma das Estâncias da região, essa em particular possui por volta dos 100 anos, localizada na região Olhos D’Água.

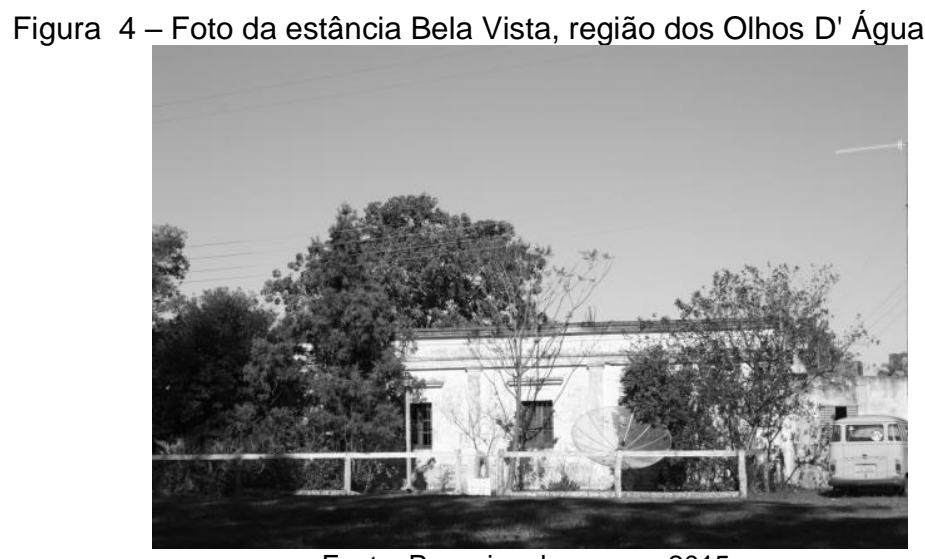

Fonte: Pesquisa de campo, 2015.

Em relação as dificuldades ecológicas, é mencionado o uso abusivo dos recursos hídricos na propriedade, por parte dos empresários rurais arrendatários: "E tivemos um tempo que sempre dava problema de falta d'água. Porque usam tudo para o arroz, e no verão que aqui não chove muito. Minhas ovelhas morrem atolada tentando tomar água nas barragens." (Trecho da entrevista com PF1).

A principal fonte de renda não é a lavoura de arroz, o pecuarista hoje é aposentado e a renda está dividida basicamente na aposentadoria e atividade da pecuária. Em relação a última, a introdução de tecnologias para o gado é baixa e se dá somente quando necessário. O manejo é de forma empírica, através do saber fazer (passado de geração em geração). Na figura 5, está relacionada a um dia de campo que houve o manejo dos pecuaristas entrevistados com o rebanho de ovinos. 
Figura 5 - Dia de manejo com ovinos em uma das estâncias na região Olhos D’Água

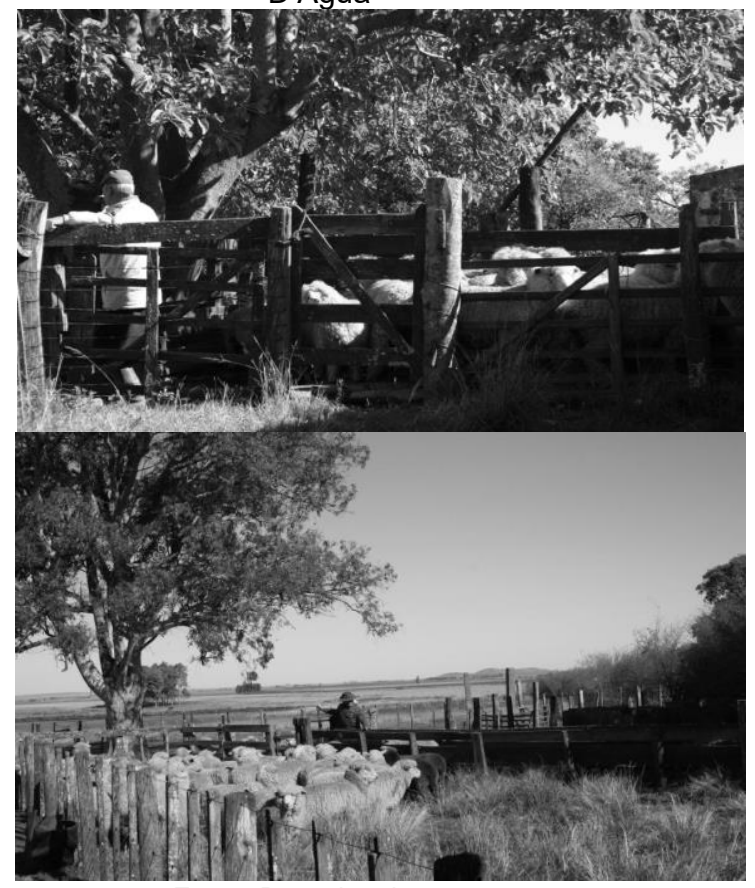

Fonte: Pesquisa de campo, 2015.

Em outro momento da conversa, foi mencionado a disposição para o cancelamento do contrato do arrendamento dos sessenta hectares, pelo motivo de degradação do solo (tendo que diminuir drasticamente a lotação de ovinos e bovinos na área arrendada). Também foi mencionado o desleixo por parte dos arrendatários pelas estradas de acesso a área (após colheita ficava de tal maneira que era impossibilitado transitar de automóvel pela estrada): "Me estraga todo o campo isso. A carretera ali, tu viu como ta né? Horrível." (Trecho da entrevista com PF1).

A avançada idade faz com que a vontade do cancelamento do contrato não ultrapasse do discurso, pois o pecuarista não consegue trabalhar com a mesma intensidade que outrora. Ele cita que sua atividade rural constante era a bovinocultura de leite.

Além das atividades já citadas, o entrevistado e sua esposa elaboravam queijo, linguiça, charque e doces caseiros (doce de leite, doce de abóbora, doce de figo, doce de pêssego e ambrosia). Comercializavam o leite in natura, ovos, doces para a comunidade local em circuitos curtos (produtor-consumidor). Atualmente sua esposa está com problemas de saúde impossibilitando a produção, já que os produtos de valor agregado eram de responsabilidade dela.

Quando mencionado as questões históricas do cultivo do arroz na região estudada, o entrevistado cita seu falecido irmão engenheiro agrônomo como o maior incentivador do cultivo na região. Essa relação das Universidades com o campo e com os modos de vidas dos agricultores e pecuaristas da região, podemos visualizar as dinâmicas, que Escobar (1999) nos possibilita entender, das transformações das 
realidades sociais, econômicas e culturais através do conhecimento científico absoluto e provedor da solução às realidades tradicionais e não desenvolvidas.

A degradação do solo por conta do arrendamento para o cultivo de arroz foi mais uma vez evidenciada pelo estudo. O pecuarista (PFA2) arrenda há dezessete anos para o arroz: "Eles me estragaram e agora eu deixei que fique só com o arroz mesmo. O pasto não nasce, e bueno ... tenho que colocar menos vaca e menos cavalos dentro do campo." (Trecho da entrevista com PFA2).

Novamente contatamos que apesar do arrendamento para o arroz, a maior parte da fonte de renda do pecuarista é proveniente da pecuária (bovinos e ovinos). $O$ pecuarista possui um trabalhador assalariado na propriedade que o ajuda. $A$ povoação de ovino e bovino teve sua lotação racionada pela falta de continuidade familiar na propriedade, por estar com mais idade e não querer mais trabalhar com a intensidade de quando era jovem.

Referente a sua relação com crédito rural, ele mencionou: "Mas há uns dois anos atrás eu peguei um crédito que a Dilma liberou, para comprar ovelha. Já vendi e já tenho o dinheiro para pagar a dívida do campo, mas não mudou muita coisa, sinceramente. Para mim, eu digo. Para mim não funcionou tanto, mas eu aumentei a população de ovino." (Trecho da entrevista com PFA2). A lógica do crédito rural não consegue ultrapassar a lógica desenvolvimentista, e o exemplo claro disso é que o entrevistado somente aderiu ao crédito por ser o único disponível no momento, entretanto não houve uma mudança nas questões sociais na propriedade, em que fizesse superar algumas das suas dificuldades.

O discurso é a favor da pecuária, apesar de arrendar o campo para a lavoura, a racionalidade econômica é diferente da racionalidade empresarial. Neste trecho ele relata que sua receita financeira não é alta, porém é suficiente para a família: "a gente não ganha muito, e se prejudica um monte, por causa do que fazem antes e depois (degradação do solo), também. O que fazem com os tratores. (Trecho da entrevista com PFA2).

O arrendamento torna-se uma opção como auxílio na renda: "Mas claro, dá para ver de longe. Mas é um dinheiro que vem todo o ano, as vezes mais e as vezes menos. Mas aí tenho meu gado, que não preciso muito, eu vivo muito bem com esse pouco que me dá." (Trecho da entrevista com PFA2).

O entrevistado acima continua com a atividade da pecuária. A cultura junto as noções de agência de cada ator também determinam o que Long (2007) cita como multiplicidade de realidades. São realidades que coexistem entre diversos interesses sociais e normativos, através de vários conhecimentos contínuos e descontínuos. Sendo de suma importância identificar os modelos que prevalecem e os que não ao decorrer do tempo em cada região.

PFA2 pensa em não arrendar mais áreas para o arroz e comenta sobre recuperar áreas: “...mas aí eu ia ter que arrumar esse campo, está muito judiado (solo degradado) e adubar e fazer algo, e não botar muito gado, por que não nasce pasto." (Trecho da entrevista com PFA2).

Os próximos entrevistados estão inseridos na dinâmica do desenvolvimento da região, entretanto, suas maiores parcelas da renda familiar provêm de auxílios governamentais e do trabalho sem carteira assinada. A trabalhadora rural (TR1) tem como sua fonte de renda: o auxílio federal do bolsa família ${ }^{5}$, serviços prestados como trabalhadora doméstica nas propriedades rurais, e trabalhos prestados de outros integrantes da família.

5 É uma transferência direta de um valor monetário à famílias que apresentam situação de pobreza extrema dentro dos limites do país 
O local onde vivem foi uma doação de um grande estancieiro já falecido. Essa localidade doada hoje possui algumas famílias que compartem da mesma área para moradia. No trecho a seguir percebe-se a dificuldade da reprodução familiar da entrevistada: "Eu trabalho por conta própria. O "marido" tem uns bichos (bovinos e ovinos) de consumo. Coisa pouca, porque a gente não tem muita coisa aqui. Tem que se virar como pode. Esse lugar aqui que a gente vive foi feito pela gente mesmo, sabe?" (Trecho da entrevista com TR).

A produção pecuária e de alimentos é para o autoconsumo. Além da dificuldade econômica, os trabalhadores rurais dessa região deixam as pequenas propriedades e passam a procurar trabalho nas cidades. O exemplo são os dois filhos maiores da entrevistada, que estão na cidade de Uruguaiana e periodicamente enviam dinheiro a família. Outros dois filhos estudam na escola do distrito. Entretanto, a escola, só possui até o quinto ano do ensino fundamental, o que significa que os outros anos são obrigados a viajar até as cidades mais próximas todos os dias (cerca de 1 hora e 30 minutos a Uruguaiana, ou 45 minutos a Quaraí, somente de ida), motivo de desistência precoce escolar das crianças na região.

O trabalhador rural reside na mesma localidade onde a entrevistada citada acima. Ele trabalha como "peão" e algumas cabeças de gado, que são criadas nos campos dos grandes pecuaristas com quem trabalha (sem carteira assinada).

Nas colheitas de arroz ele trabalha como temporário, porém com nenhum respaldo legal ou benefícios trabalhistas: "Tenho duas vacas e três cavalo. E não planto, só trabalho na colheita no início do ano. Aí eu domo (domar) os cavalos e as vezes me dão um potro (filhote de cavalo) pela doma também. Aí eu vendo depois, vou levando. Deixo o gado no campo de um patrão também." (Trecho da entrevista com TR2).

O trabalhador rural não terminou o ensino fundamental, pois a escola da região possui até o quinto ano do ensino fundamental. Após esse período é necessário viajar a cidade para concluir, fato que não ocorreu com o entrevistado pela dificuldade de viajar diariamente e deixar seu trabalho na região. Ele se queixa da falta de emprego no âmbito rural e ressalta uma estratégia de seguir trabalhando para adquirir outras cabeças de gado e uma área para poder criar seus próprios bovinos e ovinos. Esta resistência em não sair da região é o que Long (2007) denomina de capacidade de agência, é dizer, a capacidade de decisão em permanecer ou não na vendendo a mão-de-obra para fins agrícolas e/ou não agrícolas.

\section{CONSIDERAÇÕES FINAIS}

Essencialmente, o presente artigo baseia-se nas epistemologias locais, regionais e particulares de realidades subalternizadas ao longo dos séculos. Com o intuito de entender realidades desde uma perspectiva orientada aos atores, o presente trabalho conclui que existem diversos mundos de vida, diversos modos de vida e níveis de mercantilização, que derivam diferentes estratégias que resistem pela continuidade da família.

É dever dos futuros estudos de reflexão/ação de caráter somatório à sociedade, facilitar a projeção das vozes dos subalternizados, que por resistência, usam seus espaços de manobra para construírem ações e reações assegurando sua autonomia enquanto sujeitos.

6 Nomenclatura dada ao empregado assalariado que trabalha com a pecuária e outros serviços dentro da estância. 
Caracteriza-se um preocupante cenário no âmbito rural da região estudada: o envelhecimento rural e a escassez de mão-de-obra. Esses são os grandes empasses que a agricultura e pecuária familiar enfrentam à sua fixação e reprodução sócio/econômico/cultural. Como incentivar aos agricultores e pecuaristas a se fixarem no rural? Não tenho respostas a tais inquietações, entretanto, essas respostas estão devidamente sistematizadas em estratégias próprias dos atores sociais, que por décadas encontraram-se subalternizadas e delimitadas de "tradicionais", "atrasadas" e "estagnadas". Tem por habitual concordar a necessidade de (re)lembrar, (re)descobrir para (re)desenhar novas histórias, ultrapassando as tentativas falidas de políticas do desenvolvimento para alcançar a sustentação de modos de vidas. As dúvidas, as estratégias e os questionamentos emergentes transformaram-se em novas alternativas ao desenvolvimento hegemônico.

A região Olhos D’Água faz parte de um cenário preocupante onde não há atrativos que façam o meio rural uma opção para viver. A falta de apoio, organização e estrutura não favorecem a programas ou planos que revertam ou incentivem a reprodução social. Pelo contrário, o modelo hegemônico ainda continua instalandose através das promessas de desenvolvimento. Ao contrário do discurso do crescimento econômico, os territórios rurais não são exclusivamente locais de produção agropecuária, eles necessitam de atrativos que fixem as famílias, a produção e, principalmente aos jovens.

Vale acrescentar que há o distanciamento abismal entre o rural e o urbano, sobretudo referente ao acesso mínimo aos serviços públicos. O desenvolvimento rural precisa ser entendido em diversas dimensões, e não somente a produtividade econômica. O crédito rural continua relacionado a projetos produtivistas do "desenvolvimento" da "metade sul" e constatamos que os créditos rurais que alguns dos entrevistados aderiram, não ultrapassam a lógica "desenvolvimentista", não alinhando-se as necessidades dessas famílias.

O território já não possui grandes ganhos de produtividade com a lavoura de arroz. Não há mais promessas como as que quando introduziram a cultura, no caso da Revolução Verde. Já não há uma ilusão, por parte dos agricultores, que esse modelo seja o exemplo a ser seguido. O modelo hegemônico já está passando por incertezas e os agricultores resistem apoiados pela atividade da pecuária, precisamente por se tratar de uma atividade com baixa dependência de insumos e tecnologias.

As medidas que possam buscar algumas soluções não são de caráter hegemônico para todas as realidades. Cada território cria diferentes vetores que devem ser valorizados. Nas mesmas características de "atrasados" e "estagnados" em que os pecuaristas familiares e a pecuária familiar foram forjados, há subsídios empíricos a pensarmos em estratégias desde essas racionalidades e modos de vida. Mesmo caminhando por uma via penosa e até mesmo utópica, o presente estudo favoreceu subsídios para (re)pensar políticas públicas que possam valorizar esses modos de vida e até mesmo (re)inventar um âmbito socialmente digno e ecologicamente respeitoso para essas famílias rurais.

Não é questão de seguir o fluxo, e tampouco uma questão de contrariedade. Simplesmente são diferentes modos de ser e ver. Não é errado ou certo. É a capacidade de cada um definir tais conceitos.

\section{REFERÊNCIAS}

ASSOSSIAÇÃO RURAL DE URUGUAIANA. 100 Anos de História. 1. ed. Uruguaiana: Gráfica Universitária, 2006. 
BOSI, E. Memória e Sociedade: lembrança dos velhos. 3. ed., São Paulo: Companhia das Letras, 1994.

CARGNIN, A. P. Políticas de desenvolvimento regional no Rio Grande do Sul: vestígios, marcas e repercussões territoriais. Brasília: Ministério da Integração Nacional, 2014.

ESCOBAR, A. Cultura, ambiente y política en la antropología contemporánea. Instituto Colombiano de Antropología e Ministerio de Cultura. Colômbia, 1999.

ESCOBAR, A. El "postdesarrollo" como concepto y pratica social. In: MATO, D. (Org). Políticas de economia, ambiente y sociedade em tempos de globalização. Caracas: Universidade Central de Venezuela, 2005, p. 17-31. Disponível em: https://red.pucp.edu.pe/wp-content/uploads/biblioteca/090505.pdf. Acesso em: 3 maio 2015.

ESCOBAR, A. La invención del desarrollo. Popayán: Universidad del Cauca, 2012.

FOUCAULT, M. Microfísica do poder. Rio de Janeiro: Graal, 1979.

GIL, A. C. Métodos e técnicas de pesquisa social. São Paulo: Editora Atlas, 2008.

INSTITUTO BRASILEIRO DE GEORGRAFIA E ESTATÍSTICA - IBGE. Uruguaiana: panorama 2013. Disponível em: https://cidades.ibge.gov.br/brasil/rs/uruguaiana/panorama. Acesso em: 15 maio 2015.

INSTITUTO RIO GRANDENSE DO ARROZ. IRGA Produtividades Municipais safra 2014/2015. Porto Alegre. 2015. Disponível em: http://stirga2018admin.hml.rs.gov.br/upload/arquivos/201805/22093455-produtividade-municipiossafra-2014-e-2015.pdf . Acesso em: 1 maio 2015.

LATOUR, B.; WOOLGAR. S. A vida de laboratório: a produção dos atos científicos. Rio de Janeiro: Relume Dumará, 1997.

LONG, N. Sociología del desarrollo: una perspectiva centrada en el ator. Centro de Investigaciones y Estudios Superiores em Antropología Social. México: El Colegio de San Luis, 2007.

LONG, N.; PLOEG, J. D. van der. Heterogeneidade, ator e estrutura: para a reconstituição do conceito de estrutura. In: SCHNEIDER S. (Org.). Os atores do desenvolvimento rural: perspectivas teóricas e práticas sociais. Porto Alegre: Editora da UFRGS, 2011. p. 21 - 48.

MAESTRI, M. O gaúcho negro: o cativo e a fazenda pastoril. In: X CONGRESSO INTERNACIONAL - ASSOCIAÇÃO LATINO-AMERICANA DE ESTUDOS AFRICANOS E ASIÁTICOS. Rio de Janeiro: ALADAA, 2000. Anais... Rio de Janeiro, 2000. 26p. Disponível em: http://bibliotecavirtual.clacso.org.ar/ar/libros/aladaa/. Acesso em: 10 maio 2015. 
PILLAR, V. D.; LANGE, O. Os campos do Sul. Porto Alegre: UFRGS, 2015.

PLOEG, J. D. van der. El proceso de trabajo agrícola y la mercantilización. In: GUZMAN, E. S.; MOLINA, M. G. (Orgs.). Ecología, campesinato y historia. Madri: La Piqueta, 1993. p. 153 - 195.

PLOEG, J. D. van der. O modo de produção camponês. In: SCHNEIDER S. (Org.). A diversidade da Agricultura Familiar. Porto Alegre: Editora da UFRGS, 2006. p. 13 - 56.

PLOEG, J. D. van der. Camponeses e Impérios Alimentares. Lutas por autonomia e sustentabilidade na era da globalização. Porto Alegre: Ed. da Universidade (UFRGS), 2008.

RIBEIRO, C. M. Estudo do modo de vida dos pecuaristas familiares da Região da Campanha do Rio Grande do Sul. 2009. 304f. Tese (Doutorado em Desenvolvimento Rural) - Faculdade de Ciências Econômicas, Universidade Federal do Rio Grande do Sul, Porto Alegre, 2008.

SANDRINI, G. B. D. Processo de inserção dos pecuaristas familiares do Rio Grande do Sul na cadeia produtiva da carne. 2005. 178f. Dissertação (Mestrado em Desenvolvimento Rural) - Faculdade de Ciências Econômicas, Universidade Federal do Rio Grande do Sul, Porto Alegre, 2005.

SANT'ANNA, D. Atividades produtivas. In: CHOMENKO, L.; BENCKE, G. (Orgs.). Nosso Pampa desconhecido. Porto Alegre: Fundação Zoobotânica do Rio Grande do Sul, 2016. p.169 - 186.

GRAZIANO DA SILVA, J. A nova dinâmica da agricultura brasileira. Campinas, São Paulo, Brasil: Unicamp, 1996.

TOLEDO, V. M. La racionalidad Ecológica de la Producción Campesina. In. GUZMÁN, E. S.; MOLINA, M. G. (Orgs.). Ecología, Campesinado e Historia. Genealogía del Poder. Madrid: La Piqueta, 1993. p.197 - 219.

TOLEDO, V. M. Metabolismos rurales: hacia una teoría económico-ecológica de la apropiación de la naturaleza. Revista Iberoamericana de Economía Ecológica, v.7, n.1, p. 1 - 26, 2008.

TOLEDO, V. M.; BARRERA-BASSOLS, N. A memória biocultural: a importância ecológica das sabedorias tradicionais. São Paulo: Editora Expressão Popular, 2015. 